\title{
ANALISIS PERMODALAN DAN KEUNTUNGAN USAHA MIKRO KECIL MENENGAH PADA RUMAH MAKAN (STUDI KASUS) DI KOTA MANADO
}

\author{
Freddy Huibert Jacob Panelewen \\ Wenny Tilaar \\ Jolanda Kitsia Juliana Kalangi
}

\begin{tabular}{ll}
\hline Naskah diterima melalui Email Jurnal Ilmiah agrisosioekonomi@ unsrat.ac.id & $:$ Kamis, 23 Juli 2020 \\
Disetujui diterbitkan & $:$ Sabtu, 25 Juli 2020 \\
\hline
\end{tabular}

\begin{abstract}
This study aims to analyze business management based on business methods and the effect of capital on the profits of MSME restaurants. This research was conducted in March to June 2019 in Manado City, North Sulawesi Province. The selection of respondents is done deliberately (purposive sampling). Primary data collection was carried out by interviewing 50 SME restaurant business owners. Secondary data were obtained from related agencies and journal articles. The analysis is carried out by analyzing the capital management of the profits of the restaurant business (business method of business) per year and analyzing the effect of capital on profits affected by costs and revenues (using SPSS Ver.22). The results showed that the capital and wealth per year, the smallest amounted to Rp 200,000.- and the highest capital and wealth Rp 107,100,000. While the average capital and wealth of micro and small restaurant businesses is Rp.10,862,360.- per year. Costs incurred per year, the lowest amounted to Rp. 800,000.- and costs incurred the highest Rp. 161,920,000. While the average annual costs incurred by micro small and medium restaurant businesses are Rp. 31,897,600. - The lowest receipts received were Rp. 24,675,000. - and the highest received receipts were $R p .33,000,000,000$. - While the average annual revenue received by micro and small restaurant restaurants was Rp. 1,463,471,300, - Profits obtained per year, the lowest is Rp. 60,300,000. - and the highest profit is Rp. 6,000,000,000. 800, - The calculation results from the data collected produce Regression Equation $Y=863,536.6,537+5,011 X 1+3,690 X 2+0,146 X 3$. This states that the hypothesis is accepted that capital and wealth, costs and revenues have a very significant effect on profits (confidence level of 99\%). *eprm*
\end{abstract}

Keywords: Micro, Small, Medium Enterprises (SMEs), restaurants, capital, profits

\begin{abstract}
ABSTRAK
Penelitian ini bertujuan untuk menganalisis pengelolaan usaha berdasarkan metode bisnis usaha dan pengaruh modal terhadap keuntungan UMKM rumah makan. Penelitian ini dilaksanakan pada bulan Maret sampai Juni 2019 di Kota Manado Provinsi Sulawesi Utara. Pemilihan responden dilakukan secara sengaja (purposive sampling). Pengumpulan data primer dilakukan dengan wawancara pada 50 pemilik usaha UMKM Rumah Makan. Data sekunder diperoleh dari Dinas terkait dan artikel jurnal. Analisis dilakukan dengan menganalisis pengelolaan modal terhadap keuntungan usaha rumah makan (metode bisnis usaha) per tahun dan menganalisis pengaruh modal terhadap keuntungan yang dipengaruhi oleh biaya dan penerimaan (menggunakan SPSS Ver.22). Hasil penelitian menunjukkan bahwa modal dan kekayaan per tahun, paling kecil sebesar Rp 200.000.- dan modal dan kekayaan paling tinggi $\mathrm{Rp}$ 107.100.000,-. Sedangkan rata rata modal dan kekayaan usaha rumah makan mikro kecil dan menengah sebesar Rp.10.862.360.- per tahun. Biaya yang dikeluarkan per tahun, paling rendah sebesar Rp 800.000.- dan biaya yang dikeluarkan paling tinggi Rp 161.920.000.- Sedangkan rata rata biaya per tahun yang dikeluarkan usaha rumah makan mikro kecil dan menengah sebesar Rp. 31.897.600.- Penerimaan yang diterima paling rendah sebesar Rp 24.675.000.- dan penerimaan yang diterima paling tinggi Rp 33.000.000.000.- Sedangkan rata rata penerimaan per tahun yang diterima usaha rumah makan mikro kecil dan menengah sebesar Rp. 1.463.471.300,- Keuntungan yang diperoleh per tahun, paling rendah sebesar Rp.60.300.000.- dan keuntungan paling tinggi Rp.6.000.000.000.Sedangkan rata rata keuntungan pertahun dari usaha rumah makan mikro kecil dan menengah sebesar Rp.395.106.800,- Hasil perhitungan dari data yang terkumpul menghasilkan Persamaan Regresi Y= 863.536.6,537+5, $011^{\mathrm{X} 1}+3.690^{\mathrm{X} 2}+0,146^{\mathrm{X} 3}$. Hal ini menyatakan bahwa hipotesis diterima yaitu modal dan kekayaan, biaya dan penerimaan berpengaruh sangat nyata terhadap keuntungan (tingkat kepercayaan sebesar 99\%). ${ }^{* p r m *}$
\end{abstract}

Kata kunci: Usaha Mikro, Kecil, Menengah (UMKM), rumah makan, modal, keuntungan 


\section{PENDAHULUAN}

\section{Latar Belakang}

Pembangunan ekonomi dilakukan pemberdayaan pada UMKM, karena UMKM merupakan salah satu penggerak bagi pertumbuhan dan pembangunan ekonomi yang memiliki kontribusi dalam menciptakan tengan kerja dan sumber pendapatan bagi masyarakat. Kehadiran UMKM dapat meningkatkan peningkatan pendapatan masyarakat, hal ini dikerenakan sektor UMKM dapat melibatkan banyak orang dengan beragam usaha. UMKM memiliki peran penting dalam pembangunan ekonomi daerah untuk mengurangi angka penggangguran. Pemerintah daerah harus memberikan perhatian bagi tumbuh dan berkembangnya bagi lapangan usaha UMKM. Pemerintah daerah memberikan yang nyata bagi UMKM dalam mempertahankan produk yang ada dari banyak impor produk pasaran dalam negeri. Pemberdayaan salah satu tugas pemerintah untuk mengangkat serta memberikan dukungan kepada masyarakat secara nyata agar memiliki kemampuan untuk mengembangkan potensi dalam masyarakat sendiri. Berdasarkan data perkembangan industri, perdagangan dan beragam usaha di Sulawesi Utara.

Otonomi daerah memberikan kesempatan bagi daerah untuk mengoptimalkan segala potensi terbaiknya, karena setiap daerah pasti memiliki beberapa keunggulan tertentu, fleksibilitas yang dimiliki ekonomi UMKM tetap eksis dan mampu untuk melakukan usaha namum seiring dengan perkembangan jumlah UMKM dari tahun ke tahun yang semakin bertambah, disisi lain ada hal-hal yang lama kelamaan mempengaruhi usaha UMKM mempunyai kendala, hal ini disebabkan faktor internal misalnya kemampuan sumber daya manusia mengelola usaha dalam bidang manajemen seperti, kemapuan dalam bidang permodalan, teknis operasional dan administrasi usaha/akutansi. Modal dalam pengelolaan usaha selalu di identikkan dengan aliran darah tubuh manusia yang bermanfaat sebagai sumber oksigen, usaha mengalami kemajuan atau kemunduran bahkan tidak akan terjaga keberlangsungannya tampak kemampuan pengelolaan modal yang memadai dalam banyak kasus seringkali terjadi dana yang dijadikan modal usaha dalam hal ini usaha UMKM makanan tradisional, tidak diketahui secara pasti karena kekurangan kemampuan mengelola dalam menghitung secara tepat dalam pengelolaan modal. Selain itu karena usaha makanan di Manado ini di olah dengan menggunakan peralatan masak yang sudah ada, maka sulit bagi pengelola usaha membedakan barang-barang modal yang usaha dan bukan usaha khusunya dalam aspek finansial. Hanya sedikit UMKM yang mengalami perkembangan dalam hal mengelola usahnya, hal ini tak lepas dari ketidaksadaran pelaku UMKM terhadap pentingnya pengelolaan keuangan usaha. Dilihat dari jumlah unit usahanya yang sangat banyak terdapat disemua sektor ekonomi yang kontribusinya yang besar terhadap pendapatan, khusunya di daerah pedesaan dan bagi keluarga berpendapatan rendah, tidak dapat diingkari betapa pentingnya bagi pembangunan ekonomi nasional. selain itu selama ini kelompok usaha itu berperan sebagai motor penggerak yg sangat krusial bagi pembangunan ekonomi dan komunitas lokal. Pada umumnya pembangunan daerah sebagai pengelola kota masih banyak memikirkan sektor formal yang lebih mudah dikontrol, padahal sektor industri UMKM memiliki kontribusi yang nyata bagi penanggulangan masalah pengangguran dan masalah perekonomian kawasan perkotaan. ILO (Internasional Lieber Organisation) melaporkan 60\% buruh dikota-kota di negara berkembang diserap oleh sektor informal dan kegiatan UMKM. Sektor UMKM sangat penting karna mampu menciptakan pasar pasar, mengembagkan perdagangan mengelola sumber daya alam, mengurangi kemiskinan, membuka lapangan kerja, membangun masyarakat dan menghidupi keluarga mereka tanpa kontrol dan fasilitas dari pihak pemerintah daerah yang memadai. Dalam pembahasan dalan sektor UMKM tentunya tidak lepas dari permasalahan ketidakmampuan memenuhi kewajiban finansial dan keterbatasan untuk menambah modal, masalah lain yang dihadapi adalah menurunnya hasil produk, pemasaran hasil produk, dan keuntungan.

Pemerintah memberi perhatian yang sangat besar terhadap perkembangan Usaha Mikro Kecil dan Menengah (UMKM). Berbagai inisiatif selalu diusahakan oleh pemerintah melalui Kementerian Negara Koperasi dan Usaha Kecil Menengah agar semakin banyak individu mau menekuni dunia usaha dalam bentuk UMKM. Perhatian Pemerintah terhadap UMKM yang sangat besar merupakan langkah strategis yang dibutuhkan Bangsa Indonesia. Keseriusan kepedulian pemerintah terhadap UMKM dengan program-program untuk menumbuh kembangkan UMKM di Indonesia. Meskipun dukungan pemerintah Indonesia sangat besar untuk menjadikan UMKM berhasil dan berkembang bukan berarti tanpa kendala. 
Agenda ekonomi dan memperkuat landasan pembangunan berkelanjutan dan keadilan diwujudkan melalui pengembangan sistem ekonomi kerakyatan berdasarkan keadilan dengan tetap memperhatikan pemanfaatan sumber daya manusia yang optimal dan pelestarian yang mandiri.

Pembangunan ekonomi nasional bukan hanya tanggung jawab pemerintah, namun merupakan tanggung jawab bersama. Masyarakat adalah pelaku utama pembangunan dan pemerintah punya andil besar dalam hal untuk dapat mengarahkan, membimbing dan menciptakan fasilitas penunjang. Semakin sempitnya lapangan kerja merupakan penyelesaian yang tidak bisa ditunda-tunda lagi, karena penduduk merupakan aset berharga bagi bangsa dan negara.

Kemungkinan gagal dalam bisnis adalah ancaman yang selalu ada dalam usaha, tidak ada jaminan kesuksesan, tantangan yang berupa kerja keras, tekanan emosional, dan resiko meminta tingkat komitmen dan pengorbanan bagi pengusaha.

\section{Modal}

Mubyarto (1991) menyatakan modal adalah sumber sumber ekonomi di luar tenaga kerja yang dibuat oleh manusia. Kadang-kadang modal dapat dilihat dalam arti uang atau arti keseluruhan nilai daripada sumberdaya ekonomi non manusia. Modal dalam usaha pertanian dapat dibedakan antara modal sendiri dan modal pinjaman. Modal merupakan salah satu faktor produksi dalam pertanian disamping tanah, tenaga kerja, dan pengusaha. Sedangkan kredit sebagai suatu alat untuk membantu penciptaan modal. Selanjutnya menurut Kadarsan (1995) bahwa modal adalah factor produksi yang disediakan, diolah dan dikontrol dalam suatu usaha tani perusahaan agribisnis maupun usaha yang masih sederhana yang berbentuk uang kartal, giral atau dalam bentuk barang yang dipakai dalam kegiatan produksi dibidang pertanian.

\section{Penerimaan}

Mubyarto (1991) menyatakan bahwa penerimaan merupakan total dari produksi atau jasa yang dijual dikali dengan harga, sedangkan pendapatan adalah hasil penerimaan yang dikurangi dengan biaya produksi. Penerimaan dari hasil produksi mempunyai persamaan dari jumlah satuan komoditas yang diproduksi dikalikan dengan harga komoditas produk persatuan. Hal ini menunjukan bahwa tinggi rendahnya harga juga akan mempengaruhi tinggi rendahnya penerimaan.

\section{Keuntungan}

Keuntungan (laba) merupakan tujuan perusahaan, dimana dengan laba perusahaan dapat memperluas usahanya. Kemampuan perusahaan untuk memperoleh laba merupakan salah satu petunjuk tentang kualitas manajemen serta operasi perusahaan tersebut, yang berarti mencerminkan nilai perusahaan. Menurut Tampubolon (2005) menyatakan bahwa laba diperoleh dari penjualan dikurangi semua biaya operasional. Hal yang sama disampaikan Sumarsono (2003) bahwa keuntungan/laba adalah selisih antara penerimaan atau pendapatan total dan jumlah seluruh biaya. Laba merupakan posisi dasar dan penting dari ikhtisar keuangan yang memiliki berbagai macam kegunaan dalam berbagai konteks, pengertian laba itu sendiri merupakan selisih antara pengeluaran dan pemasukan. Laba perusahaan dalam hal ini dapat dilakukan dijadikan sebagai ukuran dari efisiensi dan efektifitas dalam sebuah unit kerja dikarenakan tujuan utama dari pendirian perusahaan adalah untuk memperoleh laba yang sebesar-besarnya dalam jangka pendek maupun jangka panjang. Oleh karena itu, laba suatu perusahaan khususnya pada pusat laba atau unit usaha yang menjadikan laba sebagai tujuan utamanya merupakan alat yang baik untuk mengukur prestasi pimpinan atau manajer atau dengan kata lain efisiensi dan efektifitas dari perusahaan dapat dilihat dari laba yang diraih unit tersebut.

\section{Rumusan Masalah}

Berdasarkan latar belakang diatas, maka rumusan masalah yang akan dikaji dalam penelitian ini adalah menganalisis permodalan dan keuntungan UMKM pada rumah makan di Kota Manado untuk keberlanjutan pengembangan usaha dalam keberlanjutan usaha UMKM.

\section{Tujuan Penelitian}

Tujuan dari penelitian ini adalah untuk mengetahui pengaruh modal terhadap keuntungan usaha UMKM rumah makan di kota Manado.

\section{Manfaat Penelitian}

1. Penelitian ini bermanfaat sebagai masukan bagi pelaku UMKM di Kota Manado dalam mengembangkan usahanya.

2. Penelitian ini dapat memberikan informasi pada Dinas Koperasi dan UMKM di Kota Manado dalam melakukan pembinaan, pelatihan dan bantuan yang dapat dilakukan agar UMKM di Kota Manado dapat berkembang dan dapat memberikan konstribusi terhadap peningkatan daerah dan kesejahteraan masyarakat. 


\section{METODE PENELITIAN}

\section{Metode Pegambilan Data}

Penelitian ini dilaksanakan di Kota Manado Provinsi Sulawesi Utara dengan mengadakan survei terhadap Rumah Makan Usaha UMKM dengan menggunakan metode surver Studi Kasus terhadap 50 Rumah Makan UMKM, data primer yang diambil terdiri dari keadaan pemilik usaha UMKM yang terdiri dari Pemimpin Usaha dan Anggota pekerja UMKM, sebagai data primer dan disamping itu modal dan kekayaan, biaya, penerimaan dan keuntungan yang dihasilkan oleh UMKM. Data sekunder diambil dari organisasi atau organisasi formal dinas terkait pemerintah daerah dan sumber lain seperti hasil hasil penelitian (jurnal) sebagai informasi keadaan UMKM tersebut, data primer dikumpulkan dengan cara menggunakan daftar isian, mengadakan wawancara mengobservasi langsung rumah makan terutama keadaan pengelolaan makanan dan bisnis usahanya. Data Primer ini juga dilakukan pencatatan terhadap segala sesuatu yang terjadi di setiap usaha UMKM (antara lain Pengambilan foto/gambar).

\section{Metode Analisis Data}

Data yang dikumpulkan Dianalisis dengan:

1. Menganalisis pengelolaan modal terhadap keuntungan usaha rumah makan di kota Manado. (metode bisnis usaha)

2. Menganalisis pengaruh modal terhadap keuntungan yang dipengaruhi oleh biaya dan penerimaan (menggunakan SPSS Ver.22).

\section{HASIL DAN PEMBAHASAN}

\section{Keadaan modal, biaya, penerimaan dan keuntungan UMKM Kota Manado}

1. Responden nomor satu jumlah modal yang dimiliki sebasar Rp.830.000, jumlah biaya sebesar Rp. 14.400.000, jumlah penerimaan sebesar Rp.144.000.000, jumlah keuntungan sebesar Rp.720.000.000, jumlah modal yang di tanam persatu rupiah mendapatkan keuntungan $\mathrm{Rp}$. 867.470

2. Responden nomor dua jumlah modal yang dimiliki sebasar Rp.1.330.000, jumlah biaya sebesar Rp. 14.400.000, jumlah penerimaan sebesar Rp.100.000.000, jumlah keuntungan sebesar Rp.90.000.000, jumlah modal yang di tanam persatu rupiah Rp. mendapatkan keuntungan Rp.67.669
3. Responden nomor tiga jumlah modal yang dimiliki sebasar Rp.1.860.000, jumlah biaya sebesar Rp. 16.200.000, jumlah penerimaan sebesar Rp.540.000.000, jumlah keuntungan sebesar Rp. 216.000.000, jumlah modal yang di tanam persatu rupiah $\mathrm{Rp}$. mendapatkan keuntungan Rp.116.129

4. Responden nomor empat jumlah modal yang dimiliki sebasar Rp.1.860.000, jumlah biaya sebesar Rp. 18.800.000, jumlah penerimaan sebesar Rp.56.250.000, jumlah keuntungan sebesar Rp.570.000.000, jumlah modal yang di tanam persatu rupiah $\mathrm{Rp}$. mendapatkan keuntungan Rp.306.452

5. Responden nomor lima jumlah modal yang dimiliki sebasar Rp.1.460.000, jumlah biaya sebesar Rp. 14.400.000, jumlah penerimaan sebesar Rp.24.675.000, jumlah keuntungan sebesar Rp.107.000.000, jumlah modal yang di tanam persatu rupiah $\mathrm{Rp}$. mendapatkan keuntungan Rp.73.356.

6. Responden nomor enam jumlah modal yang dimiliki sebasar Rp.1.430.000, jumlah biaya sebesar Rp. 21.600.000, jumlah penerimaan sebesar Rp.63.750.000, jumlah keuntungan sebesar Rp.306.000.000, jumlah modal yang di tanam persatu rupiah $\mathrm{Rp}$. mendapatkan keuntungan Rp.213.986.

7. Responden nomor tujuh jumlah modal yang dimiliki sebasar Rp.200.000, jumlah biaya sebesar Rp. 21.600.000, jumlah penerimaan sebesar Rp.429.450.000, jumlah keuntungan sebesar Rp.157.500.000, jumlah modal yang di tanam persatu rupiah $\mathrm{Rp}$. mendapatkan keuntungan Rp.787.500.

8. Responden nomor delapan jumlah modal yang dimiliki sebasar Rp.3.360.000, jumlah biaya sebesar Rp. 7.200.000, jumlah penerimaan sebesar Rp.495.000.000, jumlah keuntungan sebesar Rp.198.000.000, jumlah modal yang di tanam persatu rupiah $\mathrm{Rp}$. mendapatkan keuntungan Rp.58.929.

9. Responden nomor sembilan jumlah modal yang dimiliki sebasar Rp.300.000, jumlah biaya sebesar Rp. 21.600.000, jumlah penerimaan sebesar Rp.922.500.000, jumlah keuntungan sebesar Rp.303.300.000, jumlah modal yang di tanam persatu rupiah Rp. mendapatkan keuntungan Rp.1.011.000. 
10. Responden nomor sepuluh jumlah modal yang dimiliki sebasar Rp.12.750.000, jumlah biaya sebesar Rp. 39.000.000, jumlah penerimaan sebesar Rp.1.630.800.000, jumlah keuntungan sebesar Rp.369.000.000, jumlah modal yang di tanam persatu rupiah Rp. mendapatkan keuntungan Rp.28.941.

11. Responden nomor sebelas jumlah modal yang dimiliki sebasar Rp.10.240.000, jumlah biaya sebesar Rp. 39.600.000, jumlah penerimaan sebesar Rp.1.672.000.000, jumlah keuntungan sebesar Rp.396.000.000, jumlah modal yang di tanam persatu rupiah Rp. mendapatkan keuntungan Rp.38.672.

12. Responden nomor duabelas jumlah modal yang dimiliki sebasar Rp.3.350.000, jumlah biaya sebesar Rp. 39.600.000, jumlah penerimaan sebesar Rp.585.000.000, jumlah keuntungan sebesar Rp.198.000.000, jumlah modal yang di tanam persatu rupiah $\mathrm{Rp}$. mendapatkan keuntungan Rp.55.775.

13. Responden nomor tigabelas jumlah modal yang dimiliki sebasar Rp.3.100.000, jumlah biaya sebesar Rp. 21.600.000, jumlah penerimaan sebesar Rp.345.600.000, jumlah keuntungan sebesar Rp.60.300.000, jumlah modal yang di tanam persatu rupiah Rp. mendapatkan keuntungan Rp.19.452.

14. Responden nomor empatbelas jumlah modal yang dimiliki sebasar Rp.107.100.000, jumlah biaya sebesar Rp. 69.920.000, jumlah penerimaan sebesar Rp.9.176.000.000, jumlah keuntungan sebesar Rp.2.188.000.000, jumlah modal yang di tanam persatu rupiah $\mathrm{Rp}$. mendapatkan keuntungan Rp.20.430.

15. Responden nomor limabelas jumlah modal yang dimiliki sebasar Rp.107.100.000, jumlah biaya sebesar Rp. 69.920.000, jumlah penerimaan sebesar Rp.3.000.000.000, jumlah keuntungan sebesar Rp.1.000.000.000, jumlah modal yang di tanam persatu rupiah Rp. mendapatkan keuntungan Rp.9.337.

16. Responden nomor enambelas jumlah modal yang dimiliki sebasar Rp.2.700.000, jumlah biaya sebesar Rp. 14.400.000, jumlah penerimaan sebesar Rp.1.446.000.000, jumlah keuntungan sebesar Rp.315.000.000, jumlah modal yang di tanam persatu rupiah Rp. mendapatkan keuntungan Rp.166.667.
17. Responden nomor tujuhbelas jumlah modal yang dimiliki sebasar Rp.2.610.000, jumlah biaya sebesar Rp. 30.600.000, jumlah penerimaan sebesar Rp.561.000.000, jumlah keuntungan sebesar Rp.244.800.000, jumlah modal yang di tanam persatu rupiah $\mathrm{Rp}$. mendapatkan keuntungan Rp.93.793.

18. Responden nomor delapanbelas jumlah modal yang dimiliki sebasar Rp.4.960.000, jumlah biaya sebesar Rp. 30.600.000, jumlah penerimaan sebesar Rp.630.000.000, jumlah keuntungan sebesar Rp.275.000.000, jumlah modal yang di tanam persatu rupiah $\mathrm{Rp}$. mendapatkan keuntungan Rp.55.444.

19. Responden nomor sembilanbelas jumlah modal yang dimiliki sebasar Rp.3.380.000, jumlah biaya sebesar Rp. 14.400.000, jumlah penerimaan sebesar Rp.810.000.000, jumlah keuntungan sebesar Rp.226.800.000, jumlah modal yang di tanam persatu rupiah $\mathrm{Rp}$. mendapatkan keuntungan Rp.67.101.

20. Responden nomor duapuluh jumlah modal yang dimiliki sebasar Rp.2.600.000, jumlah biaya sebesar Rp. 14.400.000, jumlah penerimaan sebesar Rp.1.446.000.000, jumlah keuntungan sebesar Rp.315.000.000, jumlah modal yang di tanam persatu rupiah $\mathrm{Rp}$. mendapatkan keuntungan Rp.121.154.

21. Responden nomor duapuluh satu jumlah modal yang dimiliki sebasar Rp.7.350.000, jumlah biaya sebesar Rp. 51.120.000, jumlah penerimaan sebesar Rp.410.400.000, jumlah keuntungan sebesar Rp.288.000.000, jumlah modal yang di tanam persatu rupiah $\mathrm{Rp}$. mendapatkan keuntungan Rp.39.184.

22. Responden nomor dua puluh dua jumlah modal yang dimiliki sebesar Rp.3.900.000, jumlah biaya sebesar Rp. 57.600.000, jumlah penerimaan sebesar Rp.392.400.000, jumlah keuntungan sebesar Rp.234.400.000, jumlah modal yang di tanam persatu rupiah $\mathrm{Rp}$. mendapatkan keuntungan Rp.60.103.

23. Responden nomor dua puluh tiga jumlah modal yang dimiliki sebesar Rp.300.000, jumlah biaya sebesar Rp. 21.600.000, jumlah penerimaan sebesar Rp.707.040.000, jumlah keuntungan sebesar Rp.230.040.000, jumlah modal yang di tanam persatu rupiah $\mathrm{Rp}$. mendapatkan keuntungan Rp.766.800. 
24. Responden nomor dua puluh empat jumlah modal yang dimiliki sebesar Rp.440.000, jumlah biaya sebesar Rp. 16.560.000, jumlah penerimaan sebesar Rp.360.000.000, jumlah keuntungan sebesar Rp.180.000.000, jumlah modal yang di tanam persatu rupiah $\mathrm{Rp}$. mendapatkan keuntungan Rp.409.091.

25. Responden nomor dua puluh lima jumlah modal yang dimiliki sebesar Rp.885.000, jumlah biaya sebesar Rp. 16.560.000, jumlah penerimaan sebesar Rp.234.000.000, jumlah keuntungan sebesar Rp.81.000.000, jumlah modal yang di tanam persatu rupiah $\mathrm{Rp}$. mendapatkan keuntungan Rp.91.525.

26. Responden nomor dua puluh enam jumlah modal yang dimiliki sebesar Rp.2.180.000, jumlah biaya sebesar Rp. 14.400.000, jumlah penerimaan sebesar Rp.230.400.000, jumlah keuntungan sebesar Rp.100.800.000, jumlah modal yang di tanam persatu rupiah $\mathrm{Rp}$. mendapatkan keuntungan Rp.46.239.

27. Responden nomor dua puluh tujuh jumlah modal yang dimiliki sebesar Rp.2.460.000, jumlah biaya sebesar Rp. 21.600.000, jumlah penerimaan sebesar Rp.315.000.000, jumlah keuntungan sebesar Rp.145.800.000, jumlah modal yang di tanam persatu rupiah $\mathrm{Rp}$. mendapatkan keuntungan Rp.59.268.

28. Responden nomor dua puluh delapan jumlah modal yang dimiliki sebesar Rp.830.000, jumlah biaya sebesar Rp. 10.800.000, jumlah penerimaan sebesar Rp.270.000.000, jumlah keuntungan sebesar Rp.81.000.000, jumlah modal yang di tanam persatu rupiah $\mathrm{Rp}$. mendapatkan keuntungan Rp.97.590.

29. Responden nomor dua puluh sembilan jumlah modal yang dimiliki sebesar Rp.2.130.000, jumlah biaya sebesar Rp. 14.400.000, jumlah penerimaan sebesar Rp.238.500.000, jumlah keuntungan sebesar Rp.105.300.000, jumlah modal yang di tanam persatu rupiah Rp. mendapatkan keuntungan Rp.49.437.

30. Responden nomor tiga puluh jumlah modal yang dimiliki sebasar Rp.1.500.000, jumlah biaya sebesar Rp. 21.600.000, jumlah penerimaan sebesar Rp.675.000.000, jumlah keuntungan sebesar Rp.270.000.000, jumlah modal yang di tanam persatu rupiah $\mathrm{Rp}$. mendapatkan keuntungan Rp.180.000.
31. Responden nomor tiga puluh satu jumlah modal yang dimiliki sebesar Rp.1.589.000, jumlah biaya sebesar Rp. 21.600.000, jumlah penerimaan sebesar Rp.459.000.000, jumlah keuntungan sebesar Rp.153.000.000, jumlah modal yang di tanam persatu rupiah $\mathrm{Rp}$. mendapatkan keuntungan Rp.96.287.

32. Responden nomor tiga puluh dua jumlah modal yang dimiliki sebesar Rp.2.095.000, jumlah biaya sebesar Rp. 21.600.000, jumlah penerimaan sebesar Rp.306.000.000, jumlah keuntungan sebesar Rp.162.000.000, jumlah modal yang di tanam persatu rupiah $\mathrm{Rp}$. mendapatkan keuntungan Rp.77.327.

33. Responden nomor tiga puluh tiga jumlah modal yang dimiliki sebesar Rp.1.500.000, jumlah biaya sebesar Rp. 18.000.000, jumlah penerimaan sebesar Rp.540.000.000, jumlah keuntungan sebesar Rp.216.000.000, jumlah modal yang di tanam persatu rupiah $\mathrm{Rp}$. mendapatkan keuntungan Rp.144.000.

34. Responden nomor tiga puluh empat jumlah modal yang dimiliki sebesar Rp.2.140.000, jumlah biaya sebesar Rp. 14.400.000, jumlah penerimaan sebesar Rp.270.000.000, jumlah keuntungan sebesar Rp.118.800.000, jumlah modal yang di tanam persatu rupiah $\mathrm{Rp}$. mendapatkan keuntungan Rp.54.495.

35. Responden nomor tiga puluh lima jumlah modal yang dimiliki sebesar Rp.830.000, jumlah biaya sebesar Rp. 10.800.000, jumlah penerimaan sebesar Rp.270.000.000, jumlah keuntungan sebesar Rp.81.000.000, jumlah modal yang di tanam persatu rupiah $\mathrm{Rp}$. mendapatkan keuntungan Rp.97.590.

36. Responden nomor tiga puluh enam jumlah modal yang dimiliki sebesar Rp.1.589.000, jumlah biaya sebesar Rp. 21.600.000, jumlah penerimaan sebesar Rp.459.000.000, jumlah keuntungan sebesar Rp.153.000.000, jumlah modal yang di tanam persatu rupiah Rp. mendapatkan keuntungan Rp.96.287.

37. Responden nomor tiga puluh tujuh jumlah modal yang dimiliki sebesar Rp.1.825.000, jumlah biaya sebesar Rp. 21.600.000, jumlah penerimaan sebesar Rp.720.000.000, jumlah keuntungan sebesar Rp.288.000.000, jumlah modal yang di tanam persatu rupiah $\mathrm{Rp}$. mendapatkan keuntungan Rp.157.808. 
38. Responden nomor tiga puluh delapan jumlah modal yang dimiliki sebesar Rp.1.595.000, jumlah biaya sebesar Rp. 21.600.000, jumlah penerimaan sebesar Rp.630.000.000, jumlah keuntungan sebesar Rp.252.000.000, jumlah modal yang di tanam persatu rupiah $\mathrm{Rp}$. mendapatkan keuntungan Rp.157.994.

39. Responden nomor tiga puluh sembilan jumlah modal yang dimiliki sebesar Rp.2.050.000, jumlah biaya sebesar Rp. 18.000.000, jumlah penerimaan sebesar Rp.2.115.000.000, jumlah keuntungan sebesar Rp.765.000.000, jumlah modal yang di tanam persatu rupiah $\mathrm{Rp}$. mendapatkan keuntungan Rp.373.171.

40. Responden nomor empat puluh jumlah modal yang dimiliki sebesar Rp.2.050.000, jumlah biaya sebesar Rp. 18.000.000, jumlah penerimaan sebesar Rp.1.530.000.000, jumlah keuntungan sebesar Rp.720.000.000, jumlah modal yang di tanam persatu rupiah Rp. mendapatkan keuntungan Rp.351.220.

41. Responden nomor empat puluh satu jumlah modal yang dimiliki sebesar Rp.5.670.000, jumlah biaya sebesar Rp. 21.600.000, jumlah penerimaan sebesar Rp.748.800.000, jumlah keuntungan sebesar Rp.183.600.000, jumlah modal yang di tanam persatu rupiah $\mathrm{Rp}$. mendapatkan keuntungan Rp.32.381.

42. Responden nomor empat puluh dua jumlah modal yang dimiliki sebasar Rp.880.000, jumlah biaya sebesar Rp. 19.800.000, jumlah penerimaan sebesar Rp.500.000.000, jumlah keuntungan sebesar Rp.187.200.000, jumlah modal yang di tanam persatu rupiah $\mathrm{Rp}$. mendapatkan keuntungan Rp.212.727.

43. Responden nomor empat puluh tiga jumlah modal yang dimiliki sebesar Rp.1.430.000, jumlah biaya sebesar Rp. 16.200.000, jumlah penerimaan sebesar Rp.243.000.000, jumlah keuntungan sebesar Rp.97.200.000, jumlah modal yang di tanam persatu rupiah $\mathrm{Rp}$. mendapatkan keuntungan Rp.67.972.

44. Responden nomor empat puluh empat jumlah modal yang dimiliki sebesar Rp.3.570.000, jumlah biaya sebesar $\mathrm{Rp}$. 23.400.000, jumlah penerimaan sebesar Rp.495.000.000, jumlah keuntungan sebesar Rp.1.188.000.000, jumlah modal yang di tanam persatu rupiah Rp. mendapatkan keuntungan Rp.332.773.
45. Responden nomor empat puluh lima jumlah modal yang dimiliki sebesar Rp.1.620.000, jumlah biaya sebesar Rp. 21.600.000, jumlah penerimaan sebesar Rp.270.000.000, jumlah keuntungan sebesar Rp.90.000.000, jumlah modal yang di tanam persatu rupiah $\mathrm{Rp}$. mendapatkan keuntungan Rp.55.556.

46. Responden nomor empat puluh enam jumlah modal yang dimiliki sebesar Rp.5.660.000, jumlah biaya sebesar Rp. 25.200.000, jumlah penerimaan sebesar Rp.432.000.000, jumlah keuntungan sebesar Rp.216.000.000, jumlah modal yang di tanam persatu rupiah $\mathrm{Rp}$. mendapatkan keuntungan Rp.38.163.

47. Responden nomor empat puluh tujuh jumlah modal yang dimiliki sebesar Rp.2.145.000, jumlah biaya sebesar Rp. 18.000.000, jumlah penerimaan sebesar Rp.576.000.000, jumlah keuntungan sebesar Rp.144.000.000, jumlah modal yang di tanam persatu rupiah $\mathrm{Rp}$. mendapatkan keuntungan Rp.67.133.

48. Responden nomor empat puluh delapan jumlah modal yang dimiliki sebesar Rp.3.505.000, jumlah biaya sebesar Rp. 18.000.000, jumlah penerimaan sebesar Rp.216.000.000, jumlah keuntungan sebesar Rp.86.400.000, jumlah modal yang di tanam persatu rupiah $\mathrm{Rp}$. mendapatkan keuntungan Rp.24.650.

49. Responden nomor empat puluh sembilan jumlah modal yang dimiliki sebesar Rp.2.145.000, jumlah biaya sebesar Rp. 19.800.000, jumlah penerimaan sebesar Rp.396.000.000, jumlah keuntungan sebesar Rp.138.600.000, jumlah modal yang di tanam persatu rupiah $\mathrm{Rp}$. mendapatkan keuntungan Rp.64.615.

50. Responden nomor lima Puluh jumlah modal yang dimiliki sebesar Rp.1.495.000, jumlah biaya sebesar Rp. 21.600.000, jumlah penerimaan sebesar Rp.243.000.000, jumlah keuntungan sebesar Rp.113.400.000, jumlah modal yang di tanam persatu rupiah Rp. mendapatkan keuntungan Rp.75.853.

\section{Menganalisis pengaruh modal biaya penerimaan terhadap keuntungan melalui aplikasi SPSS ver.22 (Statistical Package for the Social Sciences)}

\section{Regression}

\begin{tabular}{lrrr}
\multicolumn{4}{c}{ Descriptive Statistics } \\
\hline KEUNTUNGAN & \multicolumn{1}{c}{ Mean } & \multicolumn{1}{c}{ Std. Deviation } & N \\
MODAL DAN & 1086236000,00 & 879622939,178 & 50 \\
KEKAYAAN & 20765259,795 & 50 \\
BIAYA & 31897600,00 & 29393186,116 & 50 \\
PENERIMAAN & 1463471300,00 & 4763956353,080 & 50 \\
\hline
\end{tabular}


Hasil Analisa pertahun usaha UMKM pada rumah makan di kota Manado menghasilkan sebagai berikut:

- Rata-rata keuntungan pertahun sebesar Rp. 395.106.800 dengan standar deviasi sebesar Rp.879.622.939,178.

- Rata-rata Modal dan kekayaan pertahun sebesar 10.862.360 dengan standar devioasi sebesar Rp.20.765.259,75.

- Rata-rata biaya pertahun sebesar Rp.31.897.600 dengan standar deviasi sebesar Rp.29.393.186,116.

- Rata rata penerimaan pertahun sebesar 1.463.471.300 dengan standar deviasi sebesar Rp. 4.763.956.353,08.

\begin{tabular}{llr}
\multicolumn{2}{c}{ Correlations } & \\
\hline & &, 988 \\
& KEUNTUNGAN &, 836 \\
Pearson & MODAL DAN KEKAYAAN &, 780 \\
Correlation & BIAYA & 1,000 \\
& PENERIMAAN &, 000 \\
& KEUNTUNGAN &, 000 \\
Sig. (1-tailed) & MODAL DAN KEKAYAAN &, 000 \\
& BIAYA & $\cdot$ \\
& PENERIMAAN & 50 \\
& KEUNTUNGAN & 50 \\
& MODAL DAN KEKAYAAN & 50 \\
$\mathrm{~N}$ & BIAYA & 50 \\
& PENERIMAAN & \\
\hline
\end{tabular}

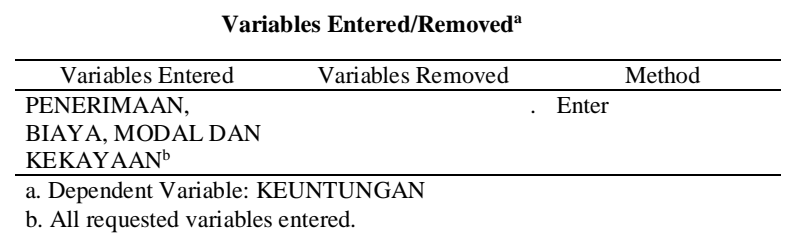

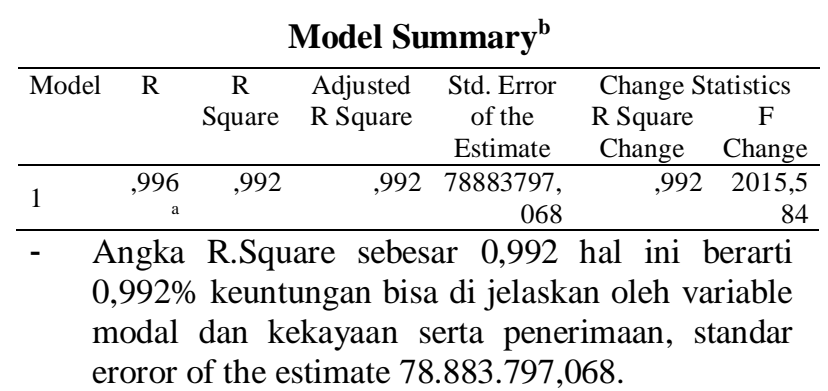

\begin{tabular}{|c|c|c|c|}
\hline \multicolumn{4}{|c|}{ Model Summary $^{\mathbf{b}}$} \\
\hline \multirow[t]{2}{*}{ Model } & \multicolumn{3}{|c|}{ Change Statistics } \\
\hline & df1 & $\mathrm{df} 2$ & Sig. F Change \\
\hline
\end{tabular}

a. Predictors: (constant), PENERIMAAN, BIAYA, MODAL DAN KEKAYAAN

b. Dependent variable: KEUNTUNGAN

\begin{tabular}{|c|c|c|c|c|c|c|}
\hline \multicolumn{7}{|c|}{ ANOVA $^{\mathrm{a}}$} \\
\hline \multicolumn{2}{|c|}{ Model } & $\begin{array}{l}\text { Sum of } \\
\text { Squares }\end{array}$ & $\mathrm{Df}$ & $\begin{array}{c}\text { Mean } \\
\text { Square }\end{array}$ & $\mathrm{F}$ & Sig. \\
\hline \multirow{8}{*}{1} & \multirow{3}{*}{$\begin{array}{l}\text { Regre } \\
\text { ssion }\end{array}$} & 37626847 & 3 & 12542282 & 2015,584 &, $000^{b}$ \\
\hline & & 18305062 & & 39435020 & & \\
\hline & & 0000,000 & & 7000,000 & & \\
\hline & \multirow{4}{*}{$\begin{array}{l}\text { Resid } \\
\text { ual }\end{array}$} & 28624205 & 46 & 62226534 & & \\
\hline & & 82373983 & & 39943441 & & \\
\hline & & 04,000 & & ,000 & & \\
\hline & & 37913089 & 49 & & & \\
\hline & Total & 24128801 & & & & \\
\hline
\end{tabular}

a. Dependent Variable: KEUNTUNGAN

b. Predictors: (Constant), PENERIMAAN, BIAYA, MODAL Dan KEKAYAAN.

Anova (analisis of varians) dengan $\mathrm{F}$ test, F Hitung lebih besar F Tabel maka, modal dan kekayaan, biaya dan penerimaan berpengaruh sangat nyata terhadap keuntungan (level of confidence) $99 \%$. Persamaan Regresi $\mathrm{y}=8$.

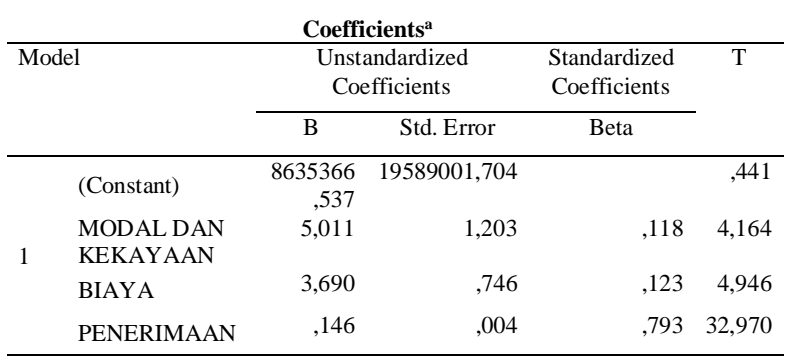

Persamaan Regresi $Y=863.536 .6,537+5,011$

$\mathrm{X} 1+3,390$

$\mathrm{X} 2+0,46$

$\mathrm{X} 3$; Y= Keuntungan X1=Modal dan Kekayaan $\mathrm{X} 2=$ BIaya, konstanta sebesar 863.536.6,537 menyatakan bahwa jika tidak ada modal dan kekayaan, biaya maka keuntungan sebesar Rp.863.536.6,537, coefisien regresi X1 5,011 menyatakan bahwa setiap penambahan modal dan kekayaan sebesar Rp.1 akan meningkatkan keuntungan sebesar Rp.5,011, coefiesien regresi X2 sebesar 3,690 menyatakan bahwa setiap penambahan biaya sebesar Rp.1 akan menaikkan keuntungan Rp.3.690 cofiesien regresi X3 sebesar 0,146 menyatakan bahwa setiap penambahan sebesar Rp.1 akan meningkatkan keuntungan sebesar 0,146 . Hal ini menyatakan bahwa hipotesis diterima disebabkan karena pengaruh modal dan kekayaan, biaya dan penerimaan sangat nyata terhadap keuntungan (sebesar 99\%) dalam tingkat kepercayaan masyarakat. 


\begin{tabular}{|c|c|c|c|c|c|}
\hline & & Coeffi & ents $\mathrm{s}^{\mathrm{a}}$ & & \\
\hline & & Sig. & $95,0 \% \mathrm{C}$ & nfidence & Corre \\
\hline & & & $\begin{array}{l}\text { Lower } \\
\text { Bound }\end{array}$ & $\begin{array}{l}\text { Upper } \\
\text { Bound } \\
\end{array}$ & $\begin{array}{l}\text { Zero- } \\
\text { order }\end{array}$ \\
\hline & (Constant) & 661 & $\begin{array}{r}- \\
30795248, \\
781\end{array}$ & $\begin{array}{r}48065981 \\
855\end{array}$ & \\
\hline 1 & $\begin{array}{l}\text { MODAL DAN } \\
\text { KEKAYAAN }\end{array}$ & ,000 & 2,589 & 7,434 & 886 \\
\hline & BIAYA & ,000 & 2,188 & 5,192 & 842 \\
\hline & PENERIMAAN & ,000 & ,138 &, 155 & 988 \\
\hline
\end{tabular}

\begin{tabular}{|c|c|c|c|c|c|}
\hline \multicolumn{6}{|c|}{ Coefficients $^{\mathrm{a}}$} \\
\hline \multirow{2}{*}{\multicolumn{2}{|c|}{ Model }} & \multirow{2}{*}{\multicolumn{2}{|c|}{ Correlations }} & \multirow{2}{*}{\multicolumn{2}{|c|}{$\begin{array}{c}\text { Collinearity } \\
\text { Statistics }\end{array}$}} \\
\hline & & & & & \\
\hline & & $\begin{array}{c}\text { Partia } \\
1 \\
\end{array}$ & Part & $\begin{array}{c}\text { Toleran } \\
\text { ce }\end{array}$ & VIF \\
\hline \multirow{5}{*}{1} & (Constant) & & & & \\
\hline & MODAL DAN & ,523 &, 053 & ,203 & 4,91 \\
\hline & KEKAYAAN & & & & 8 \\
\hline & BIAYA & ,589 & ,063 & ,264 & 3,78 \\
\hline & PENERIMAAN & ,979 & ,422 & ,284 & 3,52 \\
\hline
\end{tabular}

a. Dependent Variable: KEUNTUNGAN

\section{Coefficient Correlations $^{\mathrm{a}}$}

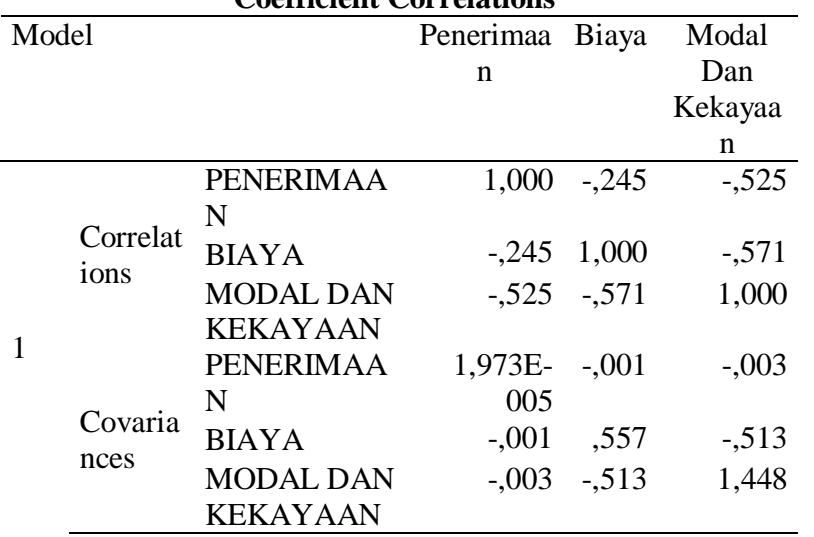

a. Dependent Variable: KEUNTUNGAN

\section{Collinearity Diagnostics ${ }^{\mathrm{a}}$}

Mod Dime Eigenva Condit Variance Proportions el nsion lue ion (Consta Modal Biay Index nt) Dan a

Kekay

\begin{tabular}{rrrrrrr} 
& & & & \multicolumn{3}{c}{ aan } \\
\hline & 1 & 2,995 & 1,000 &, 02 &, 02 &, 01 \\
& 2 &, 786 & 1,952 &, 26 &, 02 &, 00 \\
1 & 3 &, 141 & 4,603 &, 21 &, 40 &, 06 \\
& 4 &, 078 & 6,216 &, 51 &, 57 &, 93 \\
\hline
\end{tabular}

Collinearity Diagnostics ${ }^{\mathrm{a}}$

\begin{tabular}{|c|c|c|}
\hline Model & Dimension & $\begin{array}{l}\text { Variance Proportions } \\
\text { PENERIMAAN }\end{array}$ \\
\hline \multirow{4}{*}{1} & 1 & ,02 \\
\hline & 2 & 09, \\
\hline & 3 & ,89 \\
\hline & 4 & , 00 \\
\hline
\end{tabular}

a. Dependent Variable: KEUNTUNGAN

Residuals Statistics ${ }^{\mathrm{a}}$

\begin{tabular}{|c|c|c|c|c|}
\hline & Minimum & $\begin{array}{l}\text { Maximu } \\
\mathrm{m}\end{array}$ & Mean & $\begin{array}{c}\text { Std. } \\
\text { Deviatio } \\
n\end{array}$ \\
\hline Predicted & 45552224, & 5975771 & 3951068 & 8762960 \\
\hline Value & 00 & 648,00 & 00,00 & 91,781 \\
\hline $\begin{array}{l}\text { Std. Predicted } \\
\text { Value }\end{array}$ &,- 399 & 6,368 & ,000 & 1,000 \\
\hline Standard & 11512427, & 7771827 & 1881893 & 1210750 \\
\hline $\begin{array}{l}\text { Error of } \\
\text { Predicted } \\
\text { Value }\end{array}$ & 000 & 2,000 & 8,346 & 4,618 \\
\hline Adjusted & 44287516 , & 5174004 & 3797873 & 7765147 \\
\hline $\begin{array}{l}\text { Predicted } \\
\text { Value }\end{array}$ & 00 & 736,00 & 37,65 & 10,745 \\
\hline Residual & $\begin{array}{r}- \\
17377451 \\
2,000\end{array}$ & $\begin{array}{r}2324625 \\
28,000\end{array}$ &, 000 & $\begin{array}{r}7643084 \\
8,863\end{array}$ \\
\hline Std. Residual & $-2,203$ & 2,947 &, 000 & ,969 \\
\hline $\begin{array}{l}\text { Stud. } \\
\text { Residual }\end{array}$ & $-2,372$ & 3,132 &, 027 & 1,047 \\
\hline $\begin{array}{l}\text { Deleted } \\
\text { Residual }\end{array}$ & $\begin{array}{r}20152483 \\
2,000\end{array}$ & $\begin{array}{r}8259952 \\
64,000\end{array}$ & $\begin{array}{r}1531946 \\
2,350\end{array}$ & $\begin{array}{r}1443047 \\
47,910\end{array}$ \\
\hline $\begin{array}{l}\text { Stud. Deleted } \\
\text { Residual }\end{array}$ & $-2,505$ & 3,492 & ,041 & 1,107 \\
\hline $\begin{array}{l}\text { Mahal. } \\
\text { Distance }\end{array}$ & ,064 & 46,583 & 2,940 & 7,527 \\
\hline $\begin{array}{l}\text { Cook's } \\
\text { Distance }\end{array}$ &, 000 & 26,607 &, 561 & 3,759 \\
\hline $\begin{array}{l}\text { Centered } \\
\text { Leverage } \\
\text { Value }\end{array}$ & ,001 & ,951 &, 060 &, 154 \\
\hline
\end{tabular}

\begin{tabular}{lr}
\hline \multicolumn{2}{c}{ Residuals Statistics ${ }^{\mathbf{a}}$} \\
\hline Predicted Value & N \\
Std. Predicted Value & 50 \\
Standard Error of Predicted Value & 50 \\
Adjusted Predicted Value & 50 \\
Residual & 50 \\
Std. Residual & 50 \\
Stud. Residual & 50 \\
Deleted Residual & 50 \\
Stud. Deleted Residual & 50 \\
Mahal. Distance & 50 \\
Cook's Distance & 50 \\
Centered Leverage Value & 50 \\
\hline a. Dependent Variable: KEUNTUNGAN
\end{tabular}




\begin{tabular}{|c|c|c|c|}
\hline \multicolumn{4}{|c|}{ Variables Entered/Removed ${ }^{\mathrm{a}}$} \\
\hline Model & Variables Entered & $\begin{array}{l}\text { Variables } \\
\text { Removed }\end{array}$ & Method \\
\hline 1 & $\begin{array}{l}\text { PENERIMAAN, } \\
\text { BIAYA, MODAL } \\
\text { DAN } \\
\text { KEKAYAAN }^{b}\end{array}$ & & Enter \\
\hline
\end{tabular}

a. Dependent Variable: KEUNTUNGAN

b. All requested variables entered.

\section{Model Summary ${ }^{\mathrm{b}}$}

\begin{tabular}{lrrrrr}
\hline $\begin{array}{l}\text { Mod } \\
\text { el }\end{array}$ & R & $\begin{array}{c}\text { R } \\
\text { Square }\end{array}$ & $\begin{array}{r}\text { Adjusted } \\
\text { R Square }\end{array}$ & $\begin{array}{c}\text { Std. Error of } \\
\text { the Estimate }\end{array}$ & $\begin{array}{c}\text { Durbin- } \\
\text { Watson }\end{array}$ \\
\hline 1 & $.996^{\mathrm{a}}$ & .992 & .992 & 78883797.068 & 1.360 \\
\hline
\end{tabular}

a. Predictors: (Constant), PENERIMAAN, BIAYA, MODAL DAN

KEKAYAAN

b. Dependent Variable: KEUNTUNGAN

\begin{tabular}{|c|c|c|c|c|c|}
\hline \multicolumn{6}{|c|}{ Collinearity Diagnostics $^{\mathrm{a}}$} \\
\hline \multirow[t]{2}{*}{ Model } & \multirow[t]{2}{*}{ Dimension } & \multirow{2}{*}{$\begin{array}{l}\text { Eigen } \\
\text { value }\end{array}$} & \multirow{2}{*}{$\begin{array}{l}\text { Condition } \\
\text { Index }\end{array}$} & \multicolumn{2}{|c|}{ Variance Proportions } \\
\hline & & & & (Constant) & $\begin{array}{l}\text { MODAL DAN } \\
\text { KEKAYAAN }\end{array}$ \\
\hline \multirow{4}{*}{1} & 1 & 2.995 & 1.000 & .02 & .02 \\
\hline & 2 & .786 & 1.952 & .26 & .02 \\
\hline & 3 & .141 & 4.603 & .21 & .40 \\
\hline & 4 & .078 & 6.216 & .51 & .57 \\
\hline \multicolumn{6}{|c|}{ Collinearity Diagnostics ${ }^{\mathrm{a}}$} \\
\hline \multirow[t]{2}{*}{ Model } & \multirow{2}{*}{\multicolumn{2}{|c|}{ Dimension }} & \multicolumn{3}{|c|}{ Variance Proportions } \\
\hline & & & BIAY & & ENERIMAAN \\
\hline & 1 & & & .01 & .02 \\
\hline & 2 & & & .00 & .09 \\
\hline & 3 & & & .06 & .89 \\
\hline & 4 & & & .93 & .00 \\
\hline
\end{tabular}

a. Dependent Variable: KEUNTUNGAN
ANOVA $^{a}$

\begin{tabular}{|c|c|c|c|c|c|}
\hline \multicolumn{2}{|c|}{ Model } & Sum of Squares & $\mathrm{df}$ & Mean Square & $\mathrm{F}$ \\
\hline & $\begin{array}{l}\text { Regressio } \\
\mathrm{n}\end{array}$ & $\begin{array}{r}3762684718305 \\
0630000.000\end{array}$ & 3 & $\begin{array}{r}12542282394 \\
350210000.0 \\
00\end{array}$ & $\begin{array}{r}2015 . \\
584\end{array}$ \\
\hline 1 & Residual & $\begin{array}{r}2862420582373 \\
98304.000\end{array}$ & $\begin{array}{l}4 \\
6\end{array}$ & $\begin{array}{r}62226534399 \\
43443.000\end{array}$ & \\
\hline & Total & $\begin{array}{r}3791308924128 \\
8020000.000 \\
\end{array}$ & $\begin{array}{l}4 \\
9\end{array}$ & & \\
\hline \multicolumn{6}{|c|}{ ANOVA $^{a}$} \\
\hline \multicolumn{2}{|c|}{ Model } & & & Sig. & \\
\hline \multicolumn{2}{|c|}{1} & $\begin{array}{l}\text { Regression } \\
\text { Residual } \\
\text { Total }\end{array}$ & & & .000 \\
\hline
\end{tabular}

a. Dependent Variable: KEUNTUNGAN

b. Predictors: (Constant), PENERIMAAN, BIAYA, MODAL DAN KEKAYAAN

\section{Coefficients $^{\mathrm{a}}$}

\begin{tabular}{llrrr}
\hline Model & & \multicolumn{2}{c}{$\begin{array}{c}\text { Unstandardized } \\
\text { Coefficients }\end{array}$} & $\begin{array}{c}\text { Standardized } \\
\text { Coefficients }\end{array}$ \\
\cline { 3 - 5 } & & \multicolumn{1}{c}{ B } & Std. Error & \multicolumn{1}{c}{ Beta } \\
\hline \multirow{3}{*}{1} & (Constant) & 8635366. & 19589001. & \\
& MODAL DAN & 537 & 704 & \\
& KEKAYAAN & 5.011 & 1.203 & .118 \\
& BIAYA & 3.690 & .746 & .123 \\
& PENERIMAAN & .146 & .004 & .793 \\
\hline
\end{tabular}

\section{Coefficients $^{\mathrm{a}}$}

\begin{tabular}{rlrrrr}
\hline Model & & T & Sig. & \multicolumn{3}{c}{ Collinearity Statistics } \\
\cline { 5 - 7 } & & & & Tolerance & VIF \\
\hline \multirow{2}{*}{1} & (Constant) & .441 & .661 & & \\
& MODAL DAN & 4.164 & .000 & .203 & 4.918 \\
& KEKAYAAN & & & .264 & 3.788 \\
& BIAYA & 4.946 & .000 & .284 & 3.526 \\
\hline
\end{tabular}

a. Dependent Variable: KEUNTUNGAN
Residuals Statistics ${ }^{\mathbf{a}}$

\begin{tabular}{lrrr}
\hline & Minimum & Maximum & Mean \\
\hline Predicted Value & 45552224.00 & 5975771648 & 395106800 \\
Std. Predicted Value & -.399 & .00 & .00 \\
Standard Error of & 11512427.00 & 77718272.0 & 18818938 \\
Predicted Value & 0 & 00 & 346 \\
Adjusted Predicted Value & 44287516.00 & 5174004736 & 379787337 \\
& -000 \\
Residual & - & .00 & .65 \\
& 173774512.0 & 232462528. & .000 \\
Std. Residual & 00 & 000 & \\
Stud. Residual & -2.203 & 2.947 & .000 \\
& -2.372 & 3.132 & .027 \\
Deleted Residual & - & 825995264. & 15319462. \\
& 201524832.0 & 000 & 350 \\
Stud. Deleted Residual & 00 & 3.492 & .041 \\
Mahal. Distance & -2.505 & 46.583 & 2.940 \\
Cook's Distance & .064 & 26.607 & .561 \\
Centered Leverage Value & .000 & .951 & .060 \\
\hline
\end{tabular}

\section{Residuals Statistics ${ }^{\mathrm{a}}$}

\begin{tabular}{lrr}
\hline & Std. Deviation & $\mathrm{N}$ \\
\hline Predicted Value & 876296091.781 & 50 \\
Std. Predicted Value & 1.000 & 50 \\
Standard Error of Predicted & 12107504.618 & 50 \\
Value & 776514710.745 & 50 \\
Adjusted Predicted Value & 76430848.863 & 50 \\
Residual & .969 & 50 \\
Std. Residual & 1.047 & 50 \\
Stud. Residual & 144304747.910 & 50 \\
Deleted Residual & 1.107 & 50 \\
Stud. Deleted Residual & 7.527 & 50 \\
Mahal. Distance & 3.759 & 50 \\
Cook's Distance & .154 & 50 \\
Centered Leverage Value & & \\
\hline
\end{tabular}

a. Dependent Variable: KEUNTUNGAN 
Gambar Tabel 1.

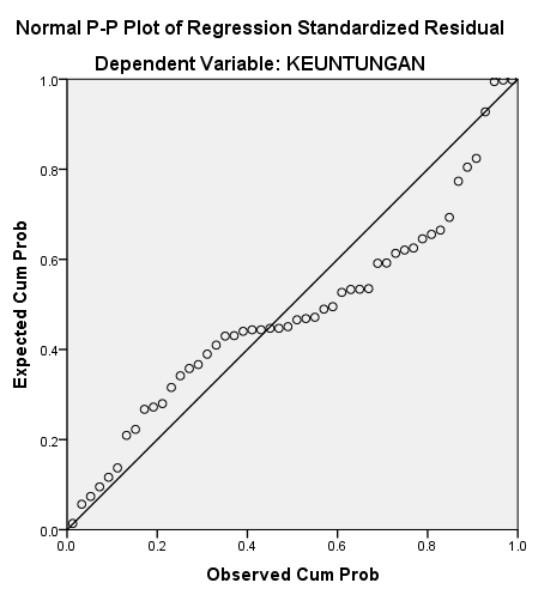

Gambar Tabel 2.

Scatterplot

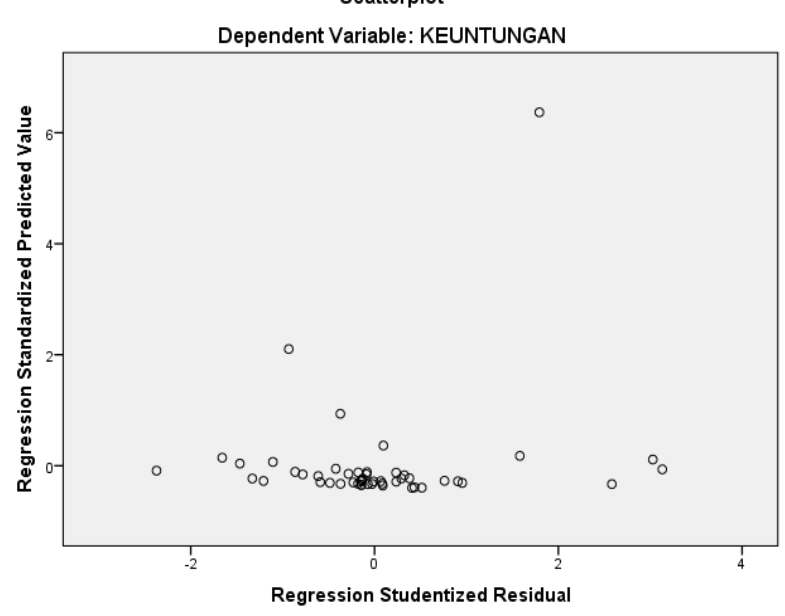

Nonparametric Correlations

Correlations

\begin{tabular}{lllr}
\hline \multicolumn{3}{c}{ Correlations } & \\
& & & \multicolumn{2}{c}{ MODAL } \\
DAN \\
KEKAYAAN
\end{tabular}

\section{Correlations}

\begin{tabular}{|c|c|c|c|c|}
\hline & & & BIAYA & $\begin{array}{l}\text { PENERIM } \\
\text { AAN }\end{array}$ \\
\hline \multirow{12}{*}{ Spearman's rho } & \multirow{3}{*}{$\begin{array}{l}\text { MODAL DAN } \\
\text { KEKAYAAN }\end{array}$} & $\begin{array}{l}\text { Correlation } \\
\text { Coefficient }\end{array}$ & .587 & $.642^{* *}$ \\
\hline & & Sig. (2-tailed) & .000 & .000 \\
\hline & & $\mathrm{N}$ & 50 & 50 \\
\hline & \multirow{3}{*}{ BIAYA } & $\begin{array}{l}\text { Correlation } \\
\text { Coefficient }\end{array}$ & $1.000^{* *}$ & .596 \\
\hline & & Sig. (2-tailed) & . & .000 \\
\hline & & $\mathrm{N}$ & 50 & 50 \\
\hline & \multirow{3}{*}{ PENERIMAAN } & $\begin{array}{l}\text { Correlation } \\
\text { Coefficient }\end{array}$ & $.596^{* *}$ & $1.000^{* *}$ \\
\hline & & Sig. (2-tailed) & .000 & . \\
\hline & & $\mathrm{N}$ & 50 & 50 \\
\hline & \multirow{3}{*}{$\begin{array}{l}\text { Unstandardized } \\
\text { Residual }\end{array}$} & $\begin{array}{l}\text { Correlation } \\
\text { Coefficient }\end{array}$ & -.271 & -.237 \\
\hline & & Sig. (2-tailed) & .057 & .097 \\
\hline & & $\mathrm{N}$ & 50 & 50 \\
\hline
\end{tabular}

\begin{tabular}{|c|c|c|c|}
\hline \multicolumn{4}{|c|}{ Correlations } \\
\hline & & & $\begin{array}{c}\text { Unstandardize } \\
\text { d Residual }\end{array}$ \\
\hline \multirow{12}{*}{$\begin{array}{l}\text { Spearman's } \\
\text { rho }\end{array}$} & \multirow{3}{*}{$\begin{array}{l}\text { MODAL DAN } \\
\text { KEKAYAAN }\end{array}$} & $\begin{array}{l}\text { Correlation } \\
\text { Coefficient }\end{array}$ & -.086 \\
\hline & & Sig. (2-tailed) & .555 \\
\hline & & $\mathrm{N}$ & 50 \\
\hline & \multirow{3}{*}{ BIAYA } & $\begin{array}{l}\text { Correlation } \\
\text { Coefficient }\end{array}$ & $-.271^{* *}$ \\
\hline & & Sig. (2-tailed) & .057 \\
\hline & & $\mathrm{N}$ & 50 \\
\hline & \multirow{3}{*}{ PENERIMAAN } & $\begin{array}{l}\text { Correlation } \\
\text { Coefficient }\end{array}$ & $-.237^{* *}$ \\
\hline & & Sig. (2-tailed) & .097 \\
\hline & & $\mathrm{N}$ & 50 \\
\hline & \multirow{3}{*}{$\begin{array}{l}\text { Unstandardized } \\
\text { Residual }\end{array}$} & $\begin{array}{l}\text { Correlation } \\
\text { Coefficient }\end{array}$ & 1.000 \\
\hline & & Sig. (2-tailed) & . \\
\hline & & $\mathrm{N}$ & 50 \\
\hline
\end{tabular}

**. Correlation is significant at the 0.01 level (2-tailed).

One-Sample Kolmogorov-Smirnov Test

\begin{tabular}{llr}
\hline & & \multicolumn{2}{c}{$\begin{array}{c}\text { Unstandardized } \\
\text { Residual }\end{array}$} \\
\hline $\mathrm{N}$ & Mean & 50 \\
Normal Parameters & & .0000000 \\
& Std. & 76430848.8629207 \\
& Deviation & 2 \\
Most Extreme & Absolute & .170 \\
Differences & Positive & .170 \\
& Negative & -.101 \\
Kolmogorov-Smirnov Z & & 1.203 \\
Asymp. Sig. (2-tailed) & & .111 \\
\hline
\end{tabular}

a. Test distribution is Normal.

b. Calculated from data. 


\section{KESIMPULAN DAN SARAN}

\section{Kesimpulan}

1. Modal dan Kekayaan: Berdasarkan hasil penelitian di lapangan, modal dan kekayaan usaha mikro kecil menengah pada rumah makan di Kota Manado sebanyak 50 rumah makan, didapatkan data rata rata modal dan kekayaan usaha rumah makan mikro kecil dan menengah sebesar Rp.10.862.360, modal dan kekayaan paling kecil sebesar $\mathrm{Rp}$ 200.000 dan modal dan kekayaan paling tinggi Rp 107.100.000.

2. Biaya: Berdasarkan hasil penelitian di lapangan, biaya yang dikeluarkan oleh usaha mikro kecil menengah pada rumah makan di Kota Manado sebanyak 50 rumah makan, didapatkan data rata rata biaya yang dikeluarkan usaha rumah makan mikro kecil dan menengah sebesar Rp. 31.897.600, biaya yang dikeluarkan paling rendah sebesar $\mathrm{Rp}$ 800.000 dan biaya yang dikeluarkan paling tinggi Rp 161.920.000.

3. Penerimaan: Berdasarkan hasil penelitian di lapangan, penerimaan yang diterima oleh usaha mikro kecil menengah pada rumah makan di Kota Manado sebanyak 50 rumah makan, didapatkan data rata rata penerimaan yang diterima usaha rumah makan mikro kecil dan menengah sebesar Rp. 1,463.471,300, penerimaan yang diterima paling rendah sebesar $\mathrm{Rp} 24,675,000$ dan penerimaan yang diterima paling tinggi Rp 33,000,000,000.

4. Keuntungan: Berdasarkan hasil penelitian di lapangan, keuntungan oleh usaha mikro kecil menengah pada rumah makan di Kota Manado sebanyak 50 rumah makan, didapatkan data rata rata keuntungan usaha rumah makan mikro kecil dan menengah sebesar Rp.395,106,800, keuntungan paling rendah sebesar Rp.60,300,000 dan keuntungan paling tinggi Rp.6,000,000,000.

Persamaan Regresi $\mathrm{Y}=$

863.536.6,537+5,011X1+3.690X2+0,146X3

$\mathrm{X} 1=5,011$ - Modal dan Kekayaan

$\mathrm{X} 2=3.690-\quad$ Biaya

$\mathrm{X} 3=0,146-\quad$ Penerimaan

$\mathrm{Y}=$ Keuntungan $\mathrm{X} 1=$ Modal dan Kekayaan X2=

Biaya, konstanta sebesar 863.536.6,537 menyatakan bahwa jika tidak ada modal dan kekayaan, biaya maka keuntungan sebesar Rp.863.536.6,537, coefisien regresi X1 5,011 menyatakan bahwa setiap penambahan modal dan kekayaan sebesar Rp.1 akan meningkatkan keuntungan sebesar Rp.5,011, coefiesien regresi X2 sebesar 3,690 menyatakan bahwa setiap penambahan biaya sebesar Rp.1 akan menaikkan keuntungan Rp.3.690 cofiesien regresi X3 sebesar 0,146 menyatakan bahwa setiap penambahan sebesar Rp.1 akan meningkatkan keuntungan sebesar 0,146. Hal ini menyatakan bahwa hipotesis diterima disebabkan karena pengaruh modal dan kekayaan, biaya dan penerimaan sangat nyata terhadap keuntungan (tingkat kepercayaan sebesar 99\%).

\section{Saran}

Saran tanggapan dan pertanyaan penulis dalam hal ini pelaku UMKM berupa rumah makan yang ada di Kota Manado, Agar para pelaku usaha UMKM rumah makan di Kota Manado, Dinas terkait membantu dan memotivasi dalam mengelola usahanya secara profesional berupa kegiatan pembekalan serta modal, pemberian informasi berbisnis dari pemerintah dan instansi terkait, ini sebaiknya dilakukan secara berkesinambungan.

\section{DAFTAR PUSTAKA}

Kadarsan, H. W. 1995. Keuangan Pertanian dan Pembiayaan perusahaan Agribisnis. Gramedia Pustaka Utama. Jakarta.

Mubyarto, 1991. Pengantar Ekonomi Pertanian. LP3ES. Jakarta.

Sumarsono, S. 2003. Ekonomi Manajemen Sumber Daya Manusia dan Ketenaga Kerjaan. Graha Ilmu. Yogyakarta.

Tampubolon, M. 2005. Manajemen Keuangan. Ghalia Indonesia. Jakarta. 